\title{
INTUITION AND INSIGHT. THE ANALYSIS OF THEIR SELECTED FEATURES WITH REFERENCE TO BERNARD LONERGAN POSITION ${ }^{1}$
}

Keywords: intuition, insight, Bernard J.F. Lonergan, receptiveness/creativity, directness/indirectness, infallibility/fallibility

Słowa kluczowe: intuicja, wgląd, Bernard J.F. Lonergan, receptywność/kreatywność, bezpośredniość/ zapośredniczenie, nieomylność/omylność

Preliminary remarks

Insight and intuition are identified by many philosophers as the same. Insight is sometimes considered as the type of intuition, for example rational insight as a kind of intellectual (non-sensory) intuition. However, when we scrutinize the history of philosophy, we can realize multiplicity of notions of intuition as well as notions of insight, their diversity and variability. It is

* Monika Walczak, dr hab., Katedra Metodologii Nauk, Wydział Filozofii Katolickiego Uniwersytetu Lubelskiego Jana Pawła II. E-mail: monika.walczak@kul.pl.

Address for correspondence: Monika Walczak, Faculty of Philosophy, The John Paul II Catholic University of Lublin, Al. Racławickie 14, 20-950 Lublin, Poland. E-mail: monika.walczak@kul.pl.

1 The issues of the role of insight in the process of knowing is addressed my book Wglad i poznanie. Epistemologia J.F. Lonergana [Insight and Knowing: Bernard J.F. Lonergan's Epistemology] (Walczak, 2012). The book is written in Polish. This paper is prepared on the base of the book, especially chapter IX. 
not easy to identify the constant set of features attributed by philosophers to insight or intuition. Moreover, the features attributed to intuition, or insight are so different as to even contradict each other. This essay illustrates of variability of notions of intuition and insight and the nature of processes of creating and changing philosophical notions. The creating and changing of notions are combined processes of defining and arguing for, or against, some theses on intuition. This essay exemplifies these processes by appealing to some notions of insight and intuition.

The first part of the paper identifies the most typical features attributed to intuition in the history of philosophy - receptiveness, passivity, immediateness, directness, self-evidence, infallibility, certainty, and/or indubitability. The second part tries initially to answer the question, Is an insight a type of intuition in the sense pointed out in the first part? In answering this question, I rely upon one of notions of insight, the one that is central to the epistemology of Bernard Lonergan, the twentieth-century philosopher located at the intersections among phenomenology, Thomism and hermeneutics. Insight is one of the most central categories of Lonergan's philosophy. The third part introduces into Lonerganian notion of insight. The fourth part considers the opposition between the receptiveness (passivity) of intuition vs. the creativity (activeness) of insight. The fifth part asks whether immediateness and directness are or can be attributes of insight. The sixth part of the paper considers self-evidence, infallibility, and indubitability, vs. fallibility and being a subject to revision, as features of insight.

\section{Typical epistemic features attributed to intuition in the history of philosophy}

In the history of philosophy we can find two fundamental attitudes toward intuition. First, it is regarded as principal tool and the most valuable (supreme) kind of knowing. Second, it is criticized as a kind of irrational knowing/knowledge and rejected. My further considerations are related to the first understanding of intuition, and those epistemic qualities of intuition that make it the privileged type of knowing/knowledge. The most substantial features attributed to intuition as the supreme kind of knowing/knowledge are: receptiveness, passivity, immediateness, directness, infallibility, selfevidence and/or indubitability. Such features are found in the notion of 
intuition as Anschauung. They are present in the notion of intuition of such philosophers as Plato, Aristotle, Saint Augustine, Thomas Aquinas, Descartes, Kant, Husserl.

\section{Is Lonergan's insight a type of intuition?}

Lonergan distances himself knowingly from the term "intuition" because it is, in his opinion, associated with the idea of knowing as looking, visualization of knowing, and mistaken epistemology with its concepts of objectivity and reality (being). He also cuts himself from Husserl's notion of intuition as looking (Anschaung, Wessenshau). For Lonergan, insight is not a kind of experience, as for many philosophers who consider it exactly as a kind of experience, in the sense of direct knowing. Insight is not a kind of experience (presentations) because it does not provide the knower with the data. Lonergan relates insight with understanding (intelligence) and reflection (judgment). He repudiates any association with typical acts of experiencing that have their pattern in looking (Cronin, 1999, pp. 301-303).

On the other hand, although Lonergan distances himself from the term "intuition", his category of "insight" can be acknowledge as a kind of synonym of the term "intuition", with respect to its content. The word "intuition" is ambiguous. In some of its meanings it is close to the Lonergan's notion of "insight", and in some of them it is not. Lonergan refers to the philosophy of Aquinas, and he points out his intelligere as the counterpart of "insight". He also attributes the inspiration for his "insight" to John Henry Newman's "illative sense". Taking into the consideration some of the meanings of both terms, their common features of insight make it possible to regard Lonergan's insight as a type of intuition. Insight and intuition both are: mental (psychical), intellectual, non-discursive, instantaneous, punctual, simple, latent, implicit, preconceptual, holistic, ordering, organizing, constructive, intentional, general (universal), direct in some aspects and in some of them indirect, unanschauliche, non-infallible (fallible), being the subject to revision, non-necessary, creative, non-receptive, interpreting, linguistically expressible, and in that sense conscious. 


\section{Lonergan's notion of insight}

Lonergan introduces his notion of insight in the context of the description of the process of knowing. Insight is a component of the process. There are different kinds of insight, but they have some common features. Therefore all insights have a certain family likeness (Lonergan, 1992, p. 4). Insight is not a extraordinary case, available only to a few people (geniuses), but it is a common event. As lumen naturale of human cognitive capacities (reason), it is found in all domains of human activity, both in formal sciences, as in common sense knowing.

Insight can be conceived in two principal ways: first, as an activity, and second, as knowledge (Lonergan, 1992, p. 16). As with other mental activities, insight is constitutive of the process of knowing, and therefore has two basic features: consciousness and intentionality. As mental activity it makes up the constitutive factor in the structure of the process of knowing (ibidem, 4) identified by Lonergan with the process of learning. It is a psychical (mental) event that occurs within various patterns of other related events. As knowledge, under determinate conditions it exhibits intentionality, revealing objects assigned to a universe of being. In case of insight as an activity, Lonergan seeks the answer to the question: what is happening when we have an insight? When we call our attention to a content of insight (knowledge), he asks, what is known when that is happening? (Lonergan, 1992, pp. 16-17).

Like "intuition" in many of its meanings, in both the Scholastic and Cartesian traditions, insight is seen as simple act, instantaneous and punctual, as non-discursive grasp of an object (something). However, Lonergan does not oppose insight to discourse (reasoning). Rather he emphasizes differences between insight and such acts as experience and judgment. He characterizes them as elements of knowing, different, then, from the complete compound of knowing (Lonergan, 1972, p. 12). Insight is just an element in knowing, an elementary moment in knowing. Insight as an elementary act is not like looking, it has not anschauliche character such as does Husserl's account of intuition.

There are some reasons for denying the anschauliche character of insight. According to Lonergan, the process of knowing consists of three levels: experience (presentations), understanding (intelligence), judgment (reflection, rationality). They are qualitatively different, but they ground 
each other. Insight emerges on the second and third level of the process of knowing, i.e. the level of intelligence and the level of reflection, but not the level of experience. It is constitutive for these levels, and they are qualitatively different from the level of experience.

Moreover, insight is determined as a kind (act) of understanding, not a kind (act) of experience. Lonergan fights against the idea of knowing as looking that reduces knowing to experience (looking), while experience is only one of its levels, just the initial one. The notion of insight as the act of understanding, constitutive for two levels of knowing appears as the counterweight against the notion of knowing as looking and idea of Anschauung as the criterion of truth. That is why Lonergan does not regard insight as a type of (direct) experience, and ipso facto he cuts himself from every tradition that uses the notion of intuition as looking (Anschaung). In Lonergan's sense, insight has nothing in common with intuition as it is understood by idealism (Kant), or intuition as it is seen by Husserl (Lonergan, 1988, p. 218).

Besides some connections between insight and Aquinas' intelligere, it also seems close to some aspects in the Aristotelian tradition of induction epagogé. Insight as activity is the act of understanding operating on experience; it is the act of organizing and constructive intelligence (Lonergan, 1992, pp. 3-4; 88). It rests on mental grasp of the general in the individual; it grasps various relations as intelligibility, identity, difference, frequency, regularities, etc.

Insight is not seen by Lonergan as a type of propositional knowledge since it is not a type of statement or judgment, i.e. intuitive, directly justified, self-evident, basic statement or judgment. Judgment arises only as the last step of the last (third) level in the process of knowing, and is the most substantial element of the level. Judging is the concluding act of the whole process of knowing, whereas insights emerge at earlier moments in the second and third level of the knowing (i.e., the levels of intelligence and reflection).

Moreover, Lonergan considers insight as preconceptual event: "insight is neither a definition nor a postulate nor an argument but a preconceptual event" (Lonergan, 1992, p. 82). If "preconceptual" means non-linguistic (what does it mean language here?), then assuming that propositional knowledge has (or should have) linguistic character, insight is not a kind of propositional knowledge. 
Lonergan's primary arguments for the claim that insight is not a type of propositional knowledge comes in two steps. First, Lonergan argues in several places that insights on the level of intelligence are presupposed in order to formulate concepts and propositions (Lonergan, 2005, pp. 193-194). He argues that insights are indispensable to the "originating" meaningfulness of language, that is, to "discovering new uses for existing words, in inventing new words, and in diffusing the discoveries and inventions" (Lonergan, 1972, pp. 255-256). Second, Lonergan also explores the nature of acts of so-called "reflective insight" (insight of the level of reflection) and their relationships to judging. There is qualitative difference between reflective insight and judgment, and that is why insight comes before a judgment and is not a judgment. Insight is prior to both statements as judgments. It exists as structural element immanent and operative within cognitional process and as reflective insight links the judgment with its justification (Lonergan, 1992, pp. 307-308).

Lonergan rejects the notion that intuitive statements that are directly justified by insights. Insight admittedly takes part in the rise of every judgment, but there is not special class of judgments (or statements) justified just by insight. It is necessary to justify every judgment (or statement), but insight is not a kind of justification in itself. Insight grasps the link between the judgment and the evidence for the judgment. It allows one to see the sufficiency of the evidence for the judgment (or statement). But insight alone does not supply that evidence.

When we count insight as a kind of non-propositional knowledge, we should consider two possibilities: the knowledge by acquaintance and the knowledge-how (the procedural knowledge). According to Lonergan, insight is not a type of knowledge by acquaintance because it is not a kind of Anschauung, perception, sensation, or experience; these are essentially connected with the level of experience. While insight is primary an act (activity), its important attribute is recurrence grounded in the knowledge-how (habitual or procedural memory), i.e. the disposition called "the habitual texture of mind" (Lonergan, 1992, p. 28).

In parallel with the dynamic structure of knowledge and its levels, Lonergan distinguishes a few basic kinds of insight. Some of them belong to the level of understanding (intelligence), others to the level of judgment (reflection). There are two kinds of insight from the level of intelligence: direct insight and inverse insight (Lonergan, 1992, p. 43). The component 
of the level of reflection is reflective insight (Lonergan, 1992, p. 304). The main criterion to distinguish between the insight of the level of intelligence and the insight of the level oif reflection is a type of questions that initiates the process of achieving particular insight. For the level of intelligence, questions for intelligence initiate the process, while for the level of reflection, it is questions for reflection. The typical insight of the level of intelligence (direct insight) answers the question for intelligence, and the typical insight of the level of reflection (reflective insight) answers the question for reflection. The question for intelligence is an object/complementation question, for example: "What is it?", "Why does it happen?", "How often?" etc. The question for reflection has as its answer a "Yes" or "No". The latter answers come in response to questions like: "Is it so?", "Is it correct?", "Is it true?", "Is it real?", etc. Admittedly, according to Lonergan, questions are linguistic expression (utterances or formulations), but primarily they are the attitude of the searching and critical mind, he calls "the detached, disinterested, pure, unrestricted desire to know" (Lonergan, 1992, pp. 372-375).

\section{Receptiveness (passivity) of intuition vs. creativity (activeness) of insight}

Lonergan's criticizes of knowing as looking and the self-evidence (intuition, Anschauung) as the criterion of truth. This implies that he does not understand insight as Anschauung. The substantial features of Anschauung are receptiveness (passivity), immediateness (directness) and infallibility (self-evidence, certainty, indubitability). According to Lonergan, insight has the opposite characteristics. It is creative (active), mediated (indirect) and fallible (it is a subject to revision). This is especially true of insights on the level of intelligence. The following considerations are focused on that kind of insight.

The creativity of insight originally comes from the activity of human desire to know (a cognitive curiosity) that "produces" questions for intelligence and initiates cognitive operations on the data of experience. Direct insights owe their creative character to their activity of "abstraction as enriching" the data and going beyond it (Lonergan, 1992, p. 112). Abstraction and insight are so closely connected that it is difficult to distinguish which is responsible for giving the order to the data, and for grasping the essential 
in the data. The order and the organization linking the data are together the work of human mind acting in abstraction and insight. Hence, they are not receptively intercepted (mirrored) from the reality. What differentiates insight from intuition as Anschauung of the (sensory, or mental) data is exactly that insight does not intercept passively its content from the reality. Rather it taces the intercepted data from the level of experience and transforms them quantitatively (supervenience), and adds to those data ordering and organizing relations. Such relations do not reside on the level of experience. Receptiveness is not the feature of insight that guarantees its "contact with reality" (objectivity) and the epistemic value. The link to reality is achieved through judgments that are grounded in reflective insights.

Direct insight adds to the empirical the abstract and the general (a priori, non-empirical) (Lonergan, 1992, p. 30). Generalization belongs to active and constructive aspects of insight because it goes beyond the data of experience. What is given is the data as individual, and direct insight generalizes and turns it into a general object. Direct insight is also not receptive because it does not assume the real presence of the object grasped in insight and presented previously by data. According to Lonergan there are different kinds of data, for example sensory data, or imaginary data. The latter are not connected with the real presence of imaginary objects but are created by imagination that can relate to possible objects, as well as to nonexisting objects. Furthermore, Lonergan uses the term "experience" in his very broad sense, for example utterances can be also the data (Lonergan, 1992, p. 299). This kind of data need not be connected to the presence of an object with which they deal.

\section{Immediateness and directness of intuition vs. the mediated character and indirectness of insight}

Lonergan criticizes the possibility of direct knowledge, including the notion of insight as direct knowledge. This is why he rejects the positions of the naive realism, empiricism, and idealism (including Cartesian idealism) on the point of the directness of knowledge. The central component of these positions is the thesis of the directness and self-evidence of sense perception as the pattern of valuable knowledge and the criterion of truth. The thesis is related to the claims, first, that every cognitive act (activity) is full knowledge 
(it is self-contained in epistemic sense), second, that reality is "the world of immediacy", and third, that objectivity is extroversion. By way of contrast, insight is not direct knowledge; it is mediated. Insight it is not intuition in the sense of Anschauung, as it is seen by empiricists and Kant (in the form of the sensory or imaginary intuition), or by idealists (in the form of the inner perception or the intuition of essences).

Insight of the level of intelligence does not guarantee direct contact with reality, allegedly in the form of the intuitive knowledge, because direct insight by itself is not yet the knowledge. It changes into knowledge on the level of reflection thanks to succeeding cognitive activities, and ultimately thanks to reflective insight and judgment. The content of insight is also not known directly because insight is not independent, direct knowledge but just the component of knowledge both as insight of the level of intelligence and as insight of the level of reflection (Lonergan, 1992, p. 457). Contrary to its name, the main kind of insight of the level of intelligence, the direct insight, does not, like Anschauung, have a direct character, but it is multiply mediated. As in the case the passiveness of insight, the criticism and rejection of directness of insight lie in impugning intuition as Anschauung and knowing as looking. In principle, Lonergan does not accept anything as direct human knowing/knowledge, and none of single cognitive acts (activities) is not knowing/knowledge because human knowing is the whole composed with many acts of three levels. Lonergan goes so far as to suggest that even the activities from the level of experience, the most often seen in the history of philosophy as direct, are not direct in an unqualified sense.

Regarding the issues of directness and mediation of insight, they can be considered in relation to insight as an act (activity) or to the content of insight. I concentrate here on the latter perspective, because the issues of directness and mediation of insight are related especially to the issues of epistemic attributes of insight. However, one should keep in mind the structure of cognitive activities and their attributes are inherited from and projected in the structure of these activities and their attributes (the principle of isomorphism). So, such mediation that is the mediation of the act of insight is also the mediation of the content of insight, when we identify the content of insight with the known (Lonergan, 1992, p. 511).

It seems paradoxical that Lonergan uses the phrase, "direct insight" when in fact it is not direct in the sense that there would be no mediation by knower (subject). In fact the knowing subject mediates the data when 
he/she works them up and adds to them the subjective element in the form of generalizing, synthetizing organization. The same data can be ordered by direct insight in different ways. In addition, a direct insight is not direct in the ordinary sense because it is both active and creative.

The content of every insight of the level of intelligence is mediated by different, earlier acts and their contents, especially by the acts from the level of experience. Every insight takes over the content of acts of experience that are its base, and adds to their content the subjective and a priori (nonempirical) element. The content of that kind of insight is also mediated by the content of questions for intelligence, because they arise as the answers to those questions. It is further mediated by contents of earlier insights and judgments because they arise only in their context and through them (Lonergan, 1992, p. 349).

This raises the problem, given the ubiquitous mediation of insights, of how the first insights in human life can arise and how their contents can be mediated if they do not have the earlier context of insights and judgments. How do their contents arise? Lonergan probably would answer that they arise from the creative power of human intelligence (mind); as every insight of the level of intelligence they are based on data.

Do forgoing consideration settle the question of non-directness of insight and its mediated character unquestionably? It seems in the sense presented so far, they do. However, maybe contents of insights, both insights of the level of intelligence as insights of the level of reflection, are directly given in the sense that the knower cannot deny that he/she grasps them, because they are given. If it would be even so, it does not mean that such contents directly relate to reality and mirror it. They need not, even because they are creative and they are not receptive.

\section{Self-evidence, infallibility, and/or indubitability of intuition vs. being the subject to revision and fallibility of insight}

Infallibility and self-evidence are not by their nature attributes of direct insight. The most distinctive features of such insight are, according to Lonergan, its liability to incompleteness, inadequacy, and error (Lonergan, 1992, p. 495). The insight does not have self-evidence as the warrant of its infallibility. Self-evidence is not the criterion of truth because questions about 
the correctness of insight and its content (i.e., questions for reflection) arise only after the direct insight has came in to being. Just with regard to insight of the level of reflection one can ask about its self-evidence (Lonergan, 1992, pp. 334-335). So, we reach here the issue of justification (grounding) of judgment, and the issue of possible justifying role of insight as well as to the problem of self-evidence, (obviousness) of insight. However, how we can verify the correctness of reflective insight? Does its correctness depend upon a still further insight of some kind? Is there a problem of a sequence ad infinitum?

Lonergan asks the question about the correctness (verification, justification) of a direct insight but not in relation to reflective insight (Lonergan, 1992, p. 308). It concerns the correctness of the content of a direct insight. The question is related to judging it content, and it precedes the judgment and conditions it. Prior to conceptual distinction between correct and incorrect (mistaken) insights is operational, on the level of the process of knowing, distinction between vulnerable and invulnerable insights. It is operational in the sense that it is operating in the process of knowing before it formulated conceptually. It is on the level of the process of knowing, and it is just secondary on the level of its knowing and conceptualization. Insight is vulnerable when there are further pertinent questions to be asked on the same issue. Further questions can lead to further insights that can complement the initial insight. They, to a greater or less extent, modify the direct insight's expression and implications. They can lead to an entirely new slant on the issue. It is only through further questions that there arise the further insights that complement, modify, or revise the initial insight. The modified series of direct insight reach the limit of being invulnerable only when there are no further pertinent questions. When insight meets the issue squarely, when it settles the matter, there are no further pertinent questions to be asked, and so there are no further insights to correct the initial insight (Lonergan, 1992, p. 309).

The absence of further pertinent questions is the criterion of invulnerability, the correctness, of insights. There are naturally questions in relation to the initial problem, but some may be questions that do not concern the problem. The knower's concentration on new questions can have different motivations, for example new other interests that draw one's attention to something different. However, these types of questions are not of concerns here. What is of interest is the situation when the knower transits to new 
questions because the initial issue is exhausted, because about it there are no further questions to be asked (Lonergan, 1992, pp. 308-309). Lonergan describes rather vaguely what kinds of questions he means. Which types of questions all types, or only questions for intelligence? It seems that if we wish to answer the question for reflection - whether the direct insight is correct - we need reach the situation of the absence of further questions for intelligence related to it, and the absence of questions about correctness of other insights related to insight in question.

The absence of further pertinent questions is a necessary condition, but not a sufficient condition for invulnerability (correctness) of an insight received by the knower. That is why this needs to be supplemented and its situated in the context of different conditions that complement it and create the base for invulnerable insight. Since, just the situatedness of the insight within the self-correcting process of knowing leading by the individual knower, the accumulation of knowledge in the domain that the insight belongs to, and the specific attitude of the knower - following transcendental precepts (Be attentive!, Be intelligent! Be reasonable! Be responsible!) - they make possible to get the valuable (correct) insight, and what is its consequence, a good judgment.

The condition of the correctness of the direct insight is the absence of further pertinent questions, because their presence could effect in the reversal of the insight. For it is not possible to guarantee impossibility of arising further questions, all insights are basically subject to revision. Moreover, it is possible that there may be unknown yet relevant data, that give rise to further questions, and in consequence they would lead to further new insights (Lonergan, 1992, p. 359).

Just as the absence of further questions asked by the knower is not enough to guarantee invulnerability of insight, likewise the demand to accept the possibility of further questions in the form of the Cartesian requirement of universal doubt goes too far. The actual absence of further questions is enough, because the kind of indubitability that demands not just the fact, but the impossibility of further questions, cannot be attained (Lonergan, 1992, pp. 433-434). "If in fact there are no further questions, then in fact the insight is invulnerable; if in fact the insight is invulnerable, then in fact the judgment approving it will be correct" (Lonergan, 1992, p. 310).

In the context of the interest of the real process of knowing of the individual knower, some specifications and supplements in the point of 
invulnerability of insight are needed. The absence of further pertinent questions in the mind of individual knower can have different psychological sources, as the deficiency in the intellectual inquisitiveness, the fact of concentration on something else, the desire to satisfy different needs then intellectual ones, etc. These sources do not give further questions a chance of arising. Such sources can be also personal features as the inclination to the rush judgment, or indecision (Lonergan, 1992, pp. 309-310). How can one neutralize the factors and keep balance between rashness and indecision? How is one to know when the balance is reached? If there were some simple recipe for answering such questions, then it would be easy to be a person of good judgment (Lonergan, 1992, p. 310). Although answers to foregoing questions is not simple, Lonergan gives some directions how to cultivate one's own abilities for evaluation of correctness of insight related to good judgment. These directions on the cultivation of good judgment are similar to Aristotle's directions in the context of practical knowledge. They constitute Loneregan's attitude toward philosophy as the educative program of improving of cognitive capacities of the individual knower.

The condition complementary to the condition of invulnerability of insight is "to give the further questions a chance to arise" (Lonergan, 1992, p. 310). So, behind issues of correct insights are issues of correct questions. Correct questions can be identified when the knower has relevant context of the accumulated knowledge, (correct) insights and judgments (is it possible to determine different then intuitively when the context is relevant?). The ability to identify correct questions seems to be mediated by the prior knowledge. Note, the idea of earlier preparation of correct insights (intuitions, judgments) by some kinds of processes and activities has been often found in the history of philosophy. According to Husserl, intuition also needs to be prepared, though it is direct knowledge. Similarly in the opinion of Aristotle, and the later tradition of virtue epistemology, good judgment is a matter of some human dispositions and the inclination to the truth. However, is there here a vicious circle? Correct insights assume correct questions, and correct questions assume correct insights? No, there is not, but it is specific holism of insights.

Lonergan responds to the objection of a vicious circle by characterizing the self-correcting process of knowing that he call also the process of learning. He interposes the notion of self-correcting process of learning just to avoid a vicious circle in the process of getting correct insights. His 
strategy is reminiscent of a hermeneutic circle suggested by the philosophical hermeneutic (Cronin, 1999, p. 234). The process of learning overcomes the vicious circle, because it is the self-correcting process, i.e. oriented on a complementing of incomplete insights and on a replacement of them with more and more complete insights correcting earlier ones. The process is oriented to a development of knowledge, on correcting mistakes, on analyzing of different alternatives, on being directed by intellectual curiosity (Lonergan, 1992, p. 311). However, it seems the solution offered by Lonergan also contains a vicious circle and additionally is a tautology, because the immanent feature of the process of knowing is that it is self-correcting, i.e. it already assumes the possibility of correcting of mistaken insights, and getting correct insights.

The process of knowing is cumulative, too. The accumulation of insights assumes the possibility of getting a new ones, but it tends to a limit. The limit is in a familiarity with the field of inquiry. This familiarity consists of insights that were arrived at earlier by the knower, and in the processes of knowing carried out by the knower (Lonergan, 1992, pp. 311-312). The accumulation of insights effects in wholes called by Lonergan "moving viewpoints"; they are reminiscent of what B. Russell called a knowledge by acquaintance, which he considered as a kind of intuition (Russell, [1912] 1959). Here Lonergan uses the terms "familiarity" or "mastery" (Lonergan, 1992, p. 313); and familiarity rests on intimacy with something, i.e. acquaintance with something.

Only the combination of two features of the process of knowing, its selfcorrecting character and accumulativeness, overcomes a vicious circle. The fact that the process of knowing is, by nature, self-correcting and cumulative has two aspects, descriptive and normative. On the one hand, it is something real and actual (the descriptive aspect), on the other hand, it is something that permanently needs work - the knower must nurture oneself as the knower (the normative aspect). In argumentation for the thesis that human knower can have correct insights, Lonergan starts from the real (actual) process of knowing; the analysis of the process of knowing reveals the presence of correct insights in the process (Lonergan, 1992, pp. 311-312).

One further remark on a possible self-evidence of insights of the level of intelligence and their infallibility: Lonergan does not find self-evidence and infallibility of insights of the second level of intelligence because truth and possible infallible truth can arise only on the third level of reflection. 
This means that direct insight by its nature does not guarantee either selfevidence, (obviousness), or infallibility of that it grasps (Lonergan, 1992, pp. 431-432). Nevertheless, it also means some direct insights, from the results of reflection and reflective insight, can prove to be infallible.

Lonergan gives his answer to the question of correctness of direct insight of the level of intelligence in Kantian terms of "the virtually unconditioned". What is the virtually unconditioned is grasped by reflective insight. The reflective insight grasps (1) a conditioned, i.e. the prospective judgment that the direct insight is correct, (2) a link between the conditioned and its conditions, what means that the direct insight is correct if it is invulnerable, and it is invulnerable if there are no further pertinent questions, and (3) the fulfilment of the conditions, namely, that the direct insight puts the end to further pertinent questioning, and that occurs in a mind of knower who takes specific cognitive attitude and it is familiar with the given object, or domain (Lonergan, 1992, p. 312).

Then, finally the issue of correctness and infallibility of insight (and judgment) of the level of intelligence comes down to issues of reflective insight and its epistemic attributes. However, this is the topic for other paper.

\section{References}

Cronin, B. (1999). Foundations of Philosophy: Lonergan's Cognitional Theory and Epistemology. Nairobi: Consolata Institute of Philosophy Press.

Lonergan, B. J. F. (1988). 'Cognitional Structure', In: F.E. Crowe and R.M. Doran (eds.), Collection. Collected Works of Bernard Lonergan. vol. 4. 205-222. Toronto: University of Toronto Press.

Lonergan, B.J.F. (1992). Insight: A Study of Human Understanding. Collected Works of Bernard Lonergan. vol. 3, F.E. Crowe and R.M. Doran. Toronto: University of Toronto Press.

Lonergan, B.J.F. (1972). Method in Theology. London: Darton, Longman $\&$ Tood.

Lonergan B.J.F. (2005), Verbum: Word and Idea in Aquinas, Collected Works of Bernard Lonergan, vol. 2, Crowe, F.E. and Doran, R.M. (eds.), Toronto: University of Toronto Press.

Russell, B. (1912). The Problems of Philosophy. London: Home University Library. 
Walczak, M. (2012). Wgląd i poznanie. Epistemologia J.F. Lonergana. (title in English: Insight and Knowing: Bernard J.F. Lonergan's Epistemology). Lublin: Wydawnictwo KUL.

\title{
INTUITION AND INSIGHT. \\ THE ANALYSIS OF THEIR SELECTED FEATURES WITH REFERENCE TO BERNARD LONERGAN POSITION
}

\begin{abstract}
Summary
The paper discusses notions of intuition and insight. The most typical features attributed to intuition in the history of philosophy - receptiveness, passivity, immediateness, directness, self-evidence, infallibility, and indubitability - are analyzed. A variability of the notion of intuition is shown, taking as its example the category of insight, central for the epistemology of Bernard J.F. Lonergan (1904-1984), the twentieth-century philosopher locating between phenomenology, Thomism and hermeneutics. Insight is still in some respects a kind of intuition although it is creative, active, mediated, indirect, fallible and open to revision.
\end{abstract}

